\title{
Case Report \\ Dizygotic Dichorionic Triamniotic Triplet Pregnancy Delivered at Full Term: An Out of Box Presentation of Triplet-A Case Report from Ethiopia
}

\author{
Melese Gezahegn Tesemma (iD) and Mikiyas Tadesse Yadeta \\ Department of Obstetrics and Gynecology, Jimma University Medical Center (JUMC), Jimma, Ethiopia \\ Correspondence should be addressed to Melese Gezahegn Tesemma; get.melese@gmail.com
}

Received 2 June 2018; Revised 31 July 2018; Accepted 1 August 2018; Published 8 August 2018

Academic Editor: Erich Cosmi

Copyright (C) 2018 Melese Gezahegn Tesemma and Mikiyas Tadesse Yadeta. This is an open access article distributed under the Creative Commons Attribution License, which permits unrestricted use, distribution, and reproduction in any medium, provided the original work is properly cited.

\begin{abstract}
The incidence of triplet is raising several hundred percent due to wide availability of fertility therapies. It is associated with different perinatal and maternal complications. The average duration of gestation and birth weight for triplet are 32.5 weeks and 1735 grams (total weight of triplet set being about $5.2 \mathrm{~kg}$ ), respectively. However, it is not uncommon to find the rarest situations in obstetrics. Here we present a case of triplet set born from gravida 5 para 4 mother at full term (GA of 39 weeks and 3 days), dated from reliable last normal menstrual period (LNMP). Each triplet has weight comparable to average weight of singleton at term. Triplets A, B, and C weigh $2.8 \mathrm{~kg}, 3 \mathrm{~kg}$, and $3.2 \mathrm{~kg}$, respectively. The triplet set weigh $9 \mathrm{~kg}$ in aggregate. Surprisingly the neonates have no perinatal complication, but the mother developed postpartum hemorrhage secondary to uterine atony. All individual triplets are large for gestational age on adjusted fetal weight standard of triplet from singleton's growth curve. Such type of triplet outcome is unique in its presentation and has never been reported in scientific literature as to the knowledge of the authors. Thus, we can consider it as "an out of box presentation of triplet". This initiates us to report the case.
\end{abstract}

\section{Introduction}

The incidence of triplet and higher order multifetal gestation is rising since 1980, primarily due to the increasingly widespread availability of infertility therapies and postponing conception to older age [1]. The incidence of triplet delivery in humans is approximately one in 6400 pregnancies and the monochorionic triplet subset may occur only once in 100,000 births [2]. Triplet pregnancy is associated with significantly increased risks of maternal and neonatal morbidity which includes preterm labor, prematurity, anemia, gestational diabetes, preeclampsia, amniotic fluid abnormalities antepartum hemorrhage, postpartum hemorrhage, still births, and perinatal deaths [3].

The average duration of gestation at delivery for singletons, twins, and triplets is 39,35 , and 32 weeks, respectively [1]. In one large series of 198 triplet pregnancies, proportion of delivery that occurred at GA of $>37$ weeks, at 32 to 37 weeks, at 29 to 31 weeks, and < 29 weeks were $5 \%$, $75 \%$, $13 \%$, and $7 \%$, respectively [4]. The mean GA and mean birth weight at delivery for triplets are 32.5 weeks and 1735 grams, respectively, as compared to singletons with 39.0 weeks and 3357 grams [5].

In one study, it is found that about $95 \%$ and $35 \%$ of triplets have low birth weight (LBW), i.e., $<2500 \mathrm{~g}$, and very low birth weight (VLBW), i.e., < 1500g, respectively. By comparison, the rates of LBW and VLBW in singletons are only $6.5 \%$ and $1.1 \%$, respectively. The average twin weighs 960 grams less than the average singleton at birth while triplets typically weigh about one-half that of infants in singleton deliveries [1].

\section{Case Report}

A 35-year-old gravida five para four mother with gestational age of 39 weeks and 3 days, dated from reliable LNMP, is admitted to Madawalabu general hospital. She is referred from health center with a diagnosis of twin gestation for better management. Her antenatal follow-up was at health center five times. She finished her immunization against tetanus and 


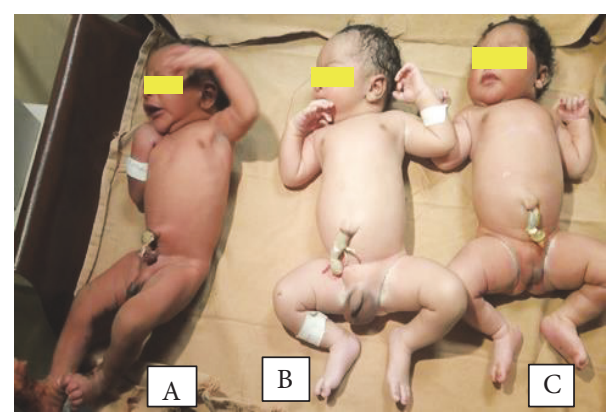

Figure 1: Picture showing triplet sets at the time of delivery. Triplets A to $\mathrm{C}$ (left to right).Triplet A: male weighing $2.8 \mathrm{Kg}$. Triplet B: male weighing $3 \mathrm{Kg}$. Triplet C: female weighing $3.2 \mathrm{Kg}$.

was taking her iron supplementation regularly. Her blood group \& $\mathrm{Rh}$ is $\mathrm{AB}+$ and preoperative hematocrit is $30 \%$ while other tests are normal. On presentation to the hospital, she has no danger signs of pregnancy like vaginal bleeding, headache, blurring of vision, and passage of liquor. She has no pushing down pain as well. She has neither personal/family history of multiple gestations nor history of taking fertility drugs. She has no personal or family history of diabetes, obesity, hypertension, and other chronic medical illnesses.

She noticed undue enlargement of abdomen and excessive increment in fetal kicks in the last trimester. She has got difficulty in undergoing daily routines during the last one month and difficulty in walking comfortably for last two weeks. Moreover she leaves her bed only with family support for the last one week due to abdominal heaviness and significantly increased body weight. Her prepregnancy weight and height were $74 \mathrm{~kg}$ and $170 \mathrm{~cm}$ making prepregnancy BMI of $25.6 \mathrm{~kg} / \mathrm{m}^{2}$ but the current weight is $98 \mathrm{~kg}$. The pregnancy is planned, wanted, and supported.

Upon examination, general appearance is well looking. Vital signs are $\mathrm{BP}=100 / 70 \mathrm{mmHg}, \mathrm{PR}=98 \mathrm{bpm}, \mathrm{RR}=22 \mathrm{bpm}$, and $\mathrm{T}^{0}=36.6^{\circ} \mathrm{C}$. On abdominal examination, abdomen is grossly distended, $\mathrm{SFH}$ measures $46 \mathrm{~cm}$ with tape meter, multiple fetal poles felt. Fetal heart beat heard at multiple sites. She has no uterine contraction. No abnormality detected in other systems. Up on scanning with obstetric U/S, there is triplet intrauterine pregnancy, two fundal placentas with two visible dividing membrane. Triplet $\mathrm{A}$ is breech in its presentation, with aggregate GA of 37 weeks +4 days, EFW $2708 \mathrm{~g}$, and biophysical profile (BPP) of $8 / 8$; triplet $\mathrm{B}$ is breech, with AGA 37 weeks + 1 day, EFW $2918 \mathrm{~g}$, and BPP of 8/8; and triplet $\mathrm{C}$ has transverse lie, with AGA 38 weeks +2 days, EFW $3104 \mathrm{~g}$, and BPP of $8 / 8$.

With the final diagnosis of full term + triplet pregnancy + mild anemia, she was prepared for elective C/S. Lower uterine segment transverse $\mathrm{C} / \mathrm{S}$ done to effect the delivery of an alive triplet sets triplet $\mathrm{A}$, male weighing $2800 \mathrm{~g}$, triplet $\mathrm{B}$, male weighing $3000 \mathrm{~g}$, and triplet $\mathrm{C}$, female weighing $3200 \mathrm{~g}$, all of them with APGAR score of $8 / 10$ and $9 / 10$ at first and fifth minutes of life. The first two triplets share the same placenta weighing $600 \mathrm{~g}$ while the $3^{\text {rd }}$ female triplet has its own placenta weighing $480 \mathrm{~g}$ but all of them having their own amniotic sac. (Figure 1). Following delivery of

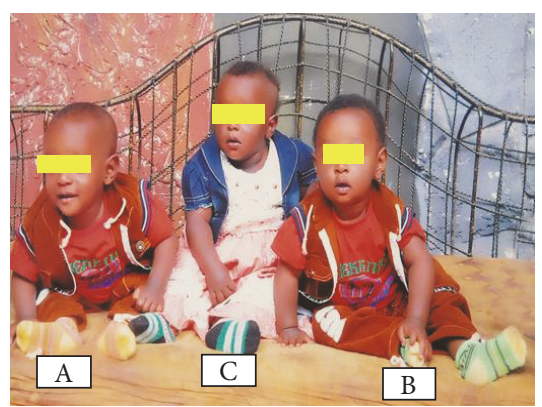

FIGURE 2: Picture showing the well-grown triplet infants at their $10^{\text {th }}$ months of life.

placentas and uterine closure, the uterus became atonic for which we put on oxytocin drip and sublingual $600 \mu \mathrm{g}$ of misoprostol. Fortunately, the uterus responded for oxytocin drip and sublingual misoprostol without requiring further management. Estimated blood loss is about $1300 \mathrm{ml}$. Uterus was massaged every 15 minutes for first 2 hours. Her postop hematocrit was $24 \%$ for which she was given therapeutic iron sulfate. Postoperative period was smooth and the mother with all the triplet was discharged on the $3^{\text {rd }}$ postop day. The infants were followed for 10 months at which time no problem with physical growth is observed; rather apparent normal neurological development is seen. All of them are in good health status as well. The picture below was taken on $10^{\text {th }}$ month of their life (Figure 2).

\section{Discussion}

This is a case of spontaneous triplet pregnancy, which is not due to ovulation induction at GA of 39 weeks and 3 days. The presence of two placenta at delivery, one separate placenta supplying female fetus and the other being shared by two male fetuses, but all of them having their own amnion, makes it dichorionic, dizygotic, triamniotic triplet set.

The growth of triplet and singleton is almost similar up to 26 weeks. From 26 to 32 weeks, the average triplet newborn has a weight corresponding to approximately the 30th percentile level compared with singletons. After 32 weeks, the growth curve of singleton gets steeper and that of triplet birth weights falls progressively behind those of singletons, reaching the 10th percentile at 38 weeks. Thus, the mean birth weight of triplets was slightly below the 10th percentile for singletons at GA of 38 weeks and beyond [6]. Accordingly, in our case not only the largest, but also the smallest triplet is above this adjusted fetal weight standard for triplet and thus, large for gestational age.

There are several factors that affect outcome in high order multiple gestations. These are maternal height, parity, number of live fetuses, placentation, and discordant growth. Height of the mother $>165 \mathrm{~cm}$, multiparty, live sets of multiple gestation, and having one placenta for each fetus will improve the birth outcome by having greater birth weight and GA at birth [7]. Death of one or two fetuses in triplet set has resulted in very preterm delivery at 31 weeks and VLBW (1380 grams) 
in one published case report [8]. In our case, the mother is multiparous and $170 \mathrm{~cm}$ tall while all the fetuses are alive, dichorionic, and triamniotic all of which are favoring good neonatal outcome.

Discordant growth among fetuses comprising the triplet gestation is common. Birth weight discordance is significantly associated with both fetal and neonatal mortality. Approximately $20 \%$ of triplet sets experience a birth weight discordance of $25-35 \%$ and nearly $10 \%$ experience severe forms of discordance (>35\%) [9]. It is only $12.5 \%$ and $6.2 \%$ in our case for the other two triplets as compared to biggest triplet. Weight gain and the pattern of weight gain during the pregnancy are important predictors of fetal weight in triplets. Better intrauterine growth for gestational age is achieved in triplet gestations with maternal weight gains of $>1.5 \mathrm{lbs}$./week before 24 weeks' gestation [10]. In our case, there was no significant birth weight discordance and the mother gained about $24 \mathrm{kgs}$ during this pregnancy predicting good neonatal outcome.

Deciding upon an upper gestational age for elective delivery is not usually an issue with triplet gestations; a large epidemiologic analysis found that only 16 percent remain undelivered at 36 weeks of gestation. The nadir of perinatal mortality for triplet pregnancies occurs at approximately 35 weeks [11]. In our case, GA at delivery was prolonged for triplet gestation. This is because the diagnosis of triplet was missed till the date of admission to the hospital as her antenatal care was at health center by midwifes where she was diagnosed to have twin gestation. Although there is no standard recommended time for elective delivery, many experts agree that it is reasonable to offer delivery of uncomplicated triplets anytime between 35 and 36 weeks as mentioned in up-to-date electronic reading material. Our case could have undergone elective caesarean delivery at GA of no later than 37 weeks had it been possible to diagnose triplet earlier in the gestation and her antenatal follow-up was in our hospital. Surprisingly, our case carried pregnancy to full term without any perinatal complication apart from maternal discomfort she faced during the latter two weeks.

\section{Conclusion}

In our case, being multipara, having nonmonochorionic placentation, absence of fetal growth discordance, maternal height of $170 \mathrm{~cm}$, and excessive weight gain of $24 \mathrm{kgs}$ during pregnancy might have contributed for this prolonged GA at birth, and large for gestational age triplet set. Delivery of triplet set at full term (39 weeks +3 days), with individual triplet weight comparable to singleton weight at term, but with no adverse perinatal outcome, is unique in its type and has never been reported in scientific literature as to the knowledge of authors. Thus, we can consider it as "an out of box presentation of triplet".

\section{Conflicts of Interest}

The authors declare that there are no conflicts of interest regarding the publication of this case report.

\section{Acknowledgments}

The authors thank the client for giving them the consent to use her clinical data for publication. Their special thank also goes to the father of the triplets who took the picture of the triplet at their $10^{\text {th }}$ month of age and send it to them for publication. The authors also thank those who are involved in the management of this patient.

\section{References}

[1] J. A. Martin, B. E. Hamilton, S. J. Ventura et al., https://www.cdc .gov/nchs/data/nvsr/nvsr60/nvsr60_01.pdf, Accessed on December 22, 2017.

[2] L. M. Ghulmiyyah, M. Perloe, M. J. Tucker, J. H. Zimmermann, D. P. Eller, and E. S. Sills, "Monochorionic-triamniotic triplet pregnancy after intracytoplasmic sperm injection, assisted hatching, and two-embryo transfer: first reported case following IVF," BMC Pregnancy and Childbirth, vol. 3, no. 4, 2003.

[3] R. Chibber, M. Fouda, W. Shishtawy et al., "Maternal and neonatal outcome in triplet, quadruplet and quintuplet gestations following ART: a 11-year study," Archives of Gynecology and Obstetrics, vol. 288, no. 4, pp. 759-767, 2013.

[4] R. B. Newman, C. Hamer, and M. C. Miller, "Outpatient triplet management: A contemporary review," American Journal of Obstetrics \& Gynecology, vol. 161, no. 3, pp. 547-555, 1989.

[5] I. Blickstein, H. M. Salihu, L. G. Keith, and G. R. Alexander, "The association between small-for-gestational age triplet Pregnancies and neonatal mortality: A novel approach to growth assessment in multiple gestations," Pediatric Research, vol. 59, no. 4, pp. 565-569, 2006.

[6] Y. Yuval, D. S. Seidman, R. Achiron et al., "Intra uterine growth of triplets as estimated from liveborn birth weight data," Ultrasound in Obstetrics \& Gynecology, vol. 6, no. 5, pp. 345348, 1995.

[7] J. P. Elliott, "High-order multiple gestations," Seminars in Perinatology, vol. 29, no. 5, pp. 305-311, 2005.

[8] J. Teliga-Czajkowska, E. Dadalska, and A. Sopliński, “Triplet pregnancy complicated by intrauterine death of two fetusescase report," Ginekologia Polska, vol. 74, no. 10, pp. 1302-1305, 2003.

[9] S. Bagchi and H. M. Salihu, "Birth weight discordance in multiple gestations: Occurrence and outcomes," Journal of Obstetrics \& Gynaecology, vol. 26, no. 4, Article ID 01443610600594724, 2006, https://doi.org/10.1080/01443610600594724.

[10] B. Luke, E. Bryan, C. Sweetland, S. Leurgans, and L. Keith, "Prenatal weight gain and the birthweight of triplets," Acta Geneticae Medicae et Gemellologiae, vol. 44, no. 2, pp. 93-101, 1995.

[11] B. Kahn, L. H. Lumey, and P. A. Zybert, "Prospective risk of fetal death in singleton, twin, and triplet gestations: implications for practice," Obstetrics \& Gynecology, vol. 102, no. 4, pp. 685-692, 2003. 


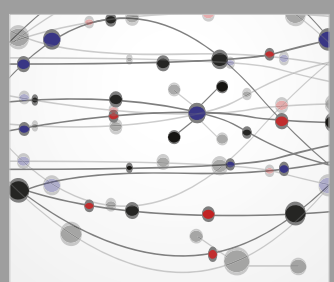

The Scientific World Journal
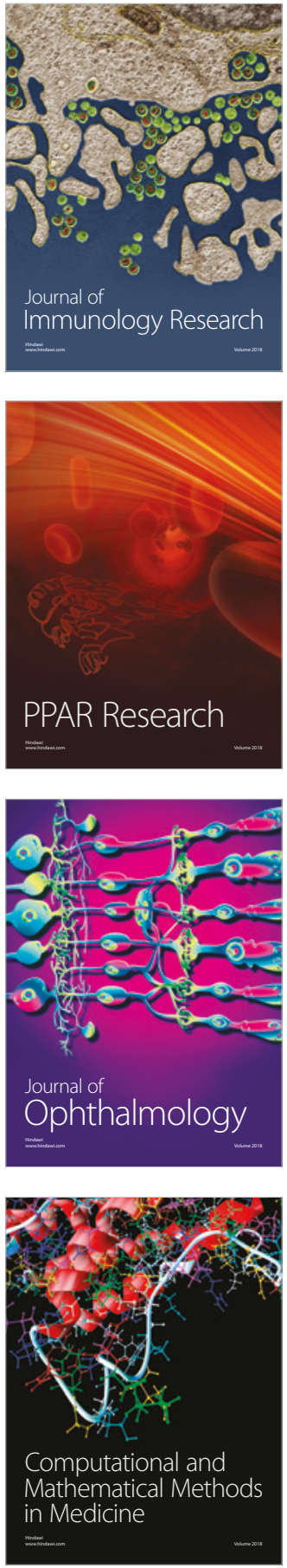

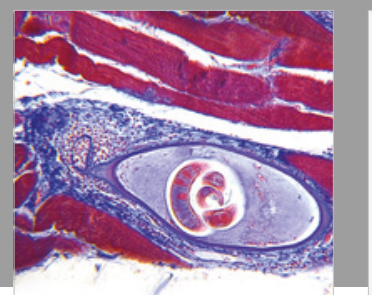

Gastroenterology Research and Practice

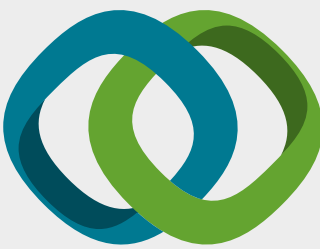

\section{Hindawi}

Submit your manuscripts at

www.hindawi.com
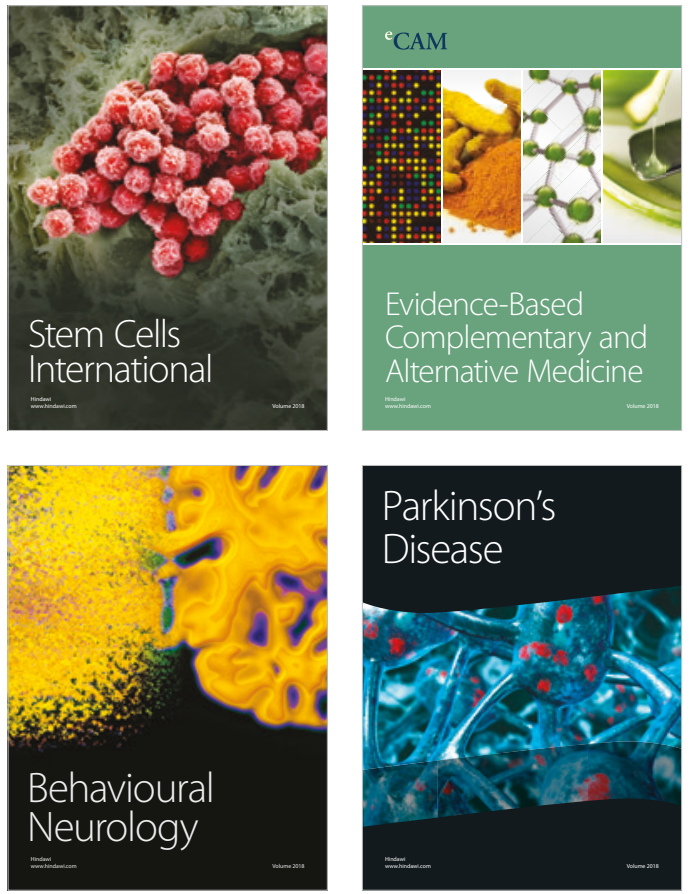

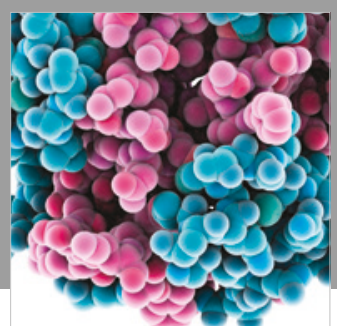

ournal of

Diabetes Research

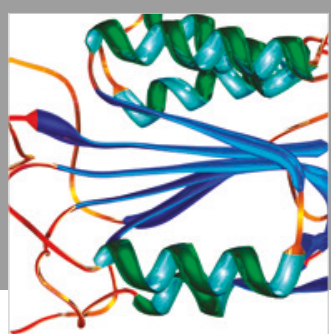

Disease Markers
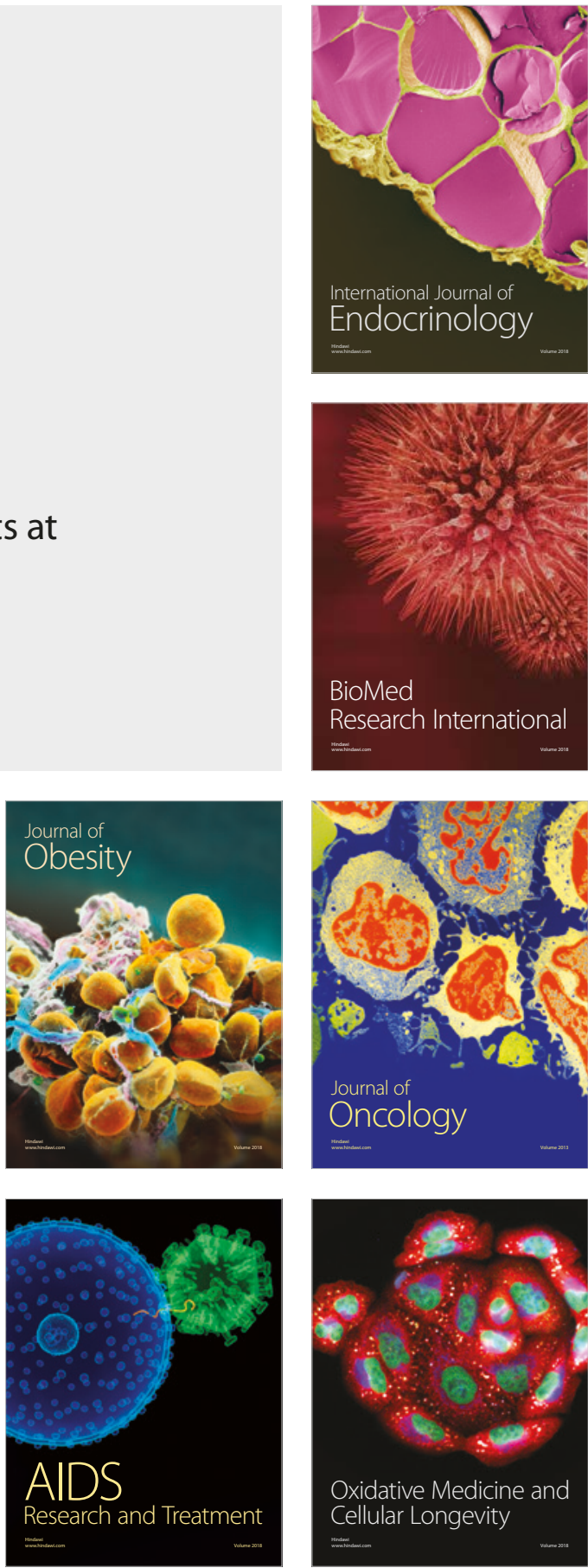